\title{
Autophagic effects of Chaihu (dried roots of Bupleurum Chinense DC or Bupleurum scorzoneraefolium WILD)
}

\author{
Betty Yuen-Kwan Law ${ }^{1}$, Jing-Fang $\mathrm{Mo}^{2}$ and Vincent Kam-Wai Wong ${ }^{1 *}$
}

\begin{abstract}
Chaihu, prepared from the dried roots of Bupleurum Chinense DC (also known as bei Chaihu in Chinese) or Bupleurum scorzoneraefolium WILD (also known as nan Chaihu in Chinese), is a herbal medicine for harmonizing and soothing gan (liver) qi stagnation. Substantial pharmacological studies have been conducted on Chaihu and its active components (saikosaponins). One of the active components of Chaihu, saikosaponin-d, exhibited anticancer effects via autophagy induction. This article reviews the pharmacological findings for the roles of autophagy in the pharmacological actions of Chaihu and saikosaponins.
\end{abstract}

Keywords: Autophagy, Chaihu, saikosaponin, Chinese Medicine, qi

\section{Introduction}

Chaihu, prepared from the dried roots of Bupleurum Chinense DC (also known as bei Chaihu in Chinese) or Bupleurum scorzoneraefolium WILD (also known as nan Chaihu in Chinese), is often prescribed as decoctions such as "xiao yao powder", "da Chaihu decoction", or "xiao Chaihu decoction" for treating chills and fevers [1-3]. Chaihu facilitates sheng (ascending) and jiang (dispersing) $q i$ to alleviate stagnation of gan (liver) $q i$ [4]. The contemporary clinical indications for Chaihu include common cold, malaria, cholecystitis, globus pharyngitis, gynecological diseases, depression, hepatitis, liver cirrhosis, pancreatitis, and hyperlipidemia $[5,6]$. Recent research has revealed the pharmacological actions of Chaihu. Specifically, Chaihu and its active components (saikosaponins) exhibited immunomodulatory $[7,8]$, antiviral [9], antipyretic [10,11], hepatoprotective $[12,13]$, anticancer [14], sedative, and analgesic [15] effects. Our recent study further revealed that saikosaponin-a (Ssa) and saikosaponin-d (Ssd), which are related to gan qi regulation $[4,13]$ can induce autophagy [16]. This article reviews the recent findings for the roles of autophagy in

\footnotetext{
* Correspondence: kawwong@must.edu.mo

'State Key Laboratory of Quality Research in Chinese Medicine, Macau University of Science and Technology, Macau, China

Full list of author information is available at the end of the article
}

the pharmacological actions of Chaihu and saikosaponins (Figure 1).

\section{Chaihu regulates qi stagnation in Chinese Medicine (CM) theory}

The CM approach to relieving symptoms (e.g., physical discomfort and emotional instability) is to soothe stagnation of gan qi [17]. Gan qi stagnation can lead to (1) distention and pain in the chest and flank, and menstrual dysregulation, (2) impaired digestive functions such as loss of appetite, dyspepsia, flatulence, and regurgitation, and (3) emotional instabilities such as depression, anxiety, and insomnia [18]. Chaihu is often prescribed to relieve the symptoms of qi stagnation in CM [5].

\section{Modern pharmacological studies on Chaihu and its active components}

Chaihu alleviates a wide spectrum of disorders in a multi-target manner through its immunomodulatory [7], antipyretic [10], hepatoprotective [13], choleretic [15], autophagy-inducing [16], sedative and analgesic [15], antihyperlipidemic [15], antiviral [9], and anticancer [14] effects.

The pharmacological effects of Chaihu are attributed to its active components, Ssa, saikosaponin-c (Ssc), and Ssd $[19,20]$. Ssa exhibits antiproliferative, anti-inflammatory, anticancer, antioxidative, and hepatoprotective effects 


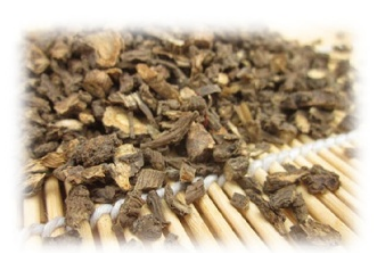

\section{CM: Chaihu (Bupleuri Radix)}

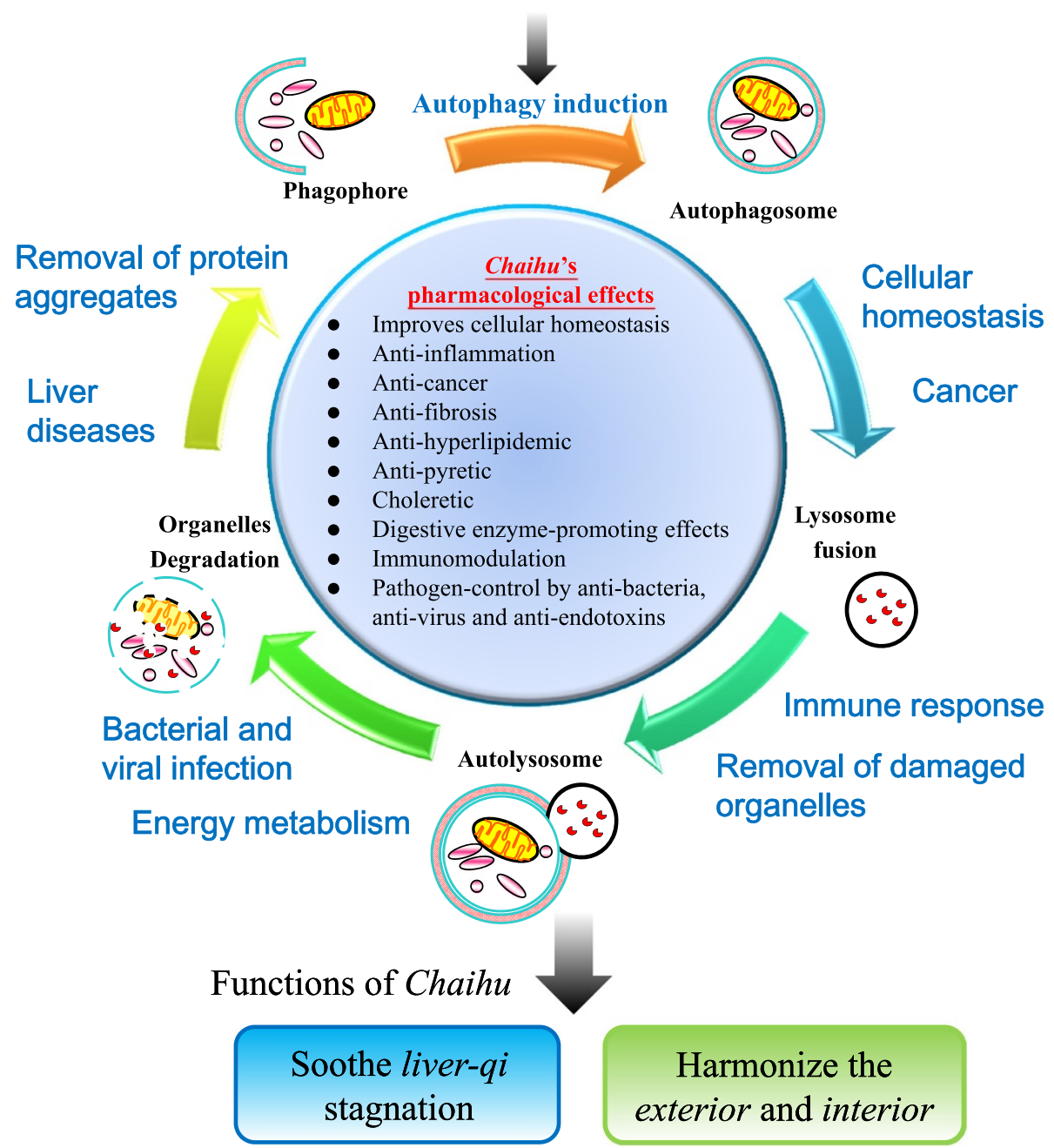

Figure 1 A schematic diagram illustrating the pharmacological effects of Chaihu through autophagy induction. With its major clinical indications in anti-inflammatory, anticancer, antifibrotic, antihyperlipidemic, and antipyretic functions, Chaihu exhibits its pharmacological effects by regulating balanced cellular homeostasis via autophagy induction, leading to harmonization and modulation of qi in the human body.

[21-26]. Ssc induces umbilical vein endothelial cell proliferation, migration, and capillary vascularization [27], and possesses anti-hepatitis effects [28]. Ssd also exhibits immunomodulatory, antiproliferative, and anticancer effects [29-32]. In particular, Ssd induces autophagy and autophagic cell death in apoptosis-defective cells via direct inhibition of sarcoplasmic/endoplasmic reticulum $\mathrm{Ca}^{2+}$ ATPase pump (SERCA) and mammalian target of rapamycin (mTOR), with disruption of calcium homeostasis and induction of endoplasmic reticulum (ER) stress [16].

\section{Autophagy in health and diseases}

Autophagy has been highlighted for its protective roles in various physiological and pathological conditions including (1) cellular homeostasis and genome stability maintenance, (2) immunomodulation, (3) hepatoprotection and aggregate removal, (4) cancers, and (5) emotional 
instability conditions [33-35]. Autophagic regulation is mainly responsible for maintenance of normal cellular and hormonal homeostasis, defense against pathogen invasion, and protection against toxic protein aggregate accumulation, and beneficial improvements in all of these at the cellular level are related to improved $q i$ stagnation (Table 1).

Newborn mice under starvation showed immediate increases of autophagy in various tissues, which returned to the basal levels after nutrient supply restoration [36-38]. Mice deficient in autophagy-related gene (Atg) 5 showed a substantial increase in nutrition deprivationinduced death, suggesting an essential role of autophagy in energy maintenance [39]. Autophagy is a protective mechanism that eliminates abnormal proteins and defective organelles such as mitochondria, peroxisomes, or ER membranes. For example, hepatocytes from Atg7knockout mice exhibited accumulation of abnormal mitochondria and ER structures [40], and associated cellular degeneration [39]. A recent study further revealed essential roles of autophagy in limiting DNA damage and chromosome instability, and failure of the autophagy process can result in carcinogenesis or cell death [41].

\section{Chaihu-mediated autophagy induction}

Maintenance of normal homeostasis by defense against pathogen infections is critical. Fever is an immune response initiated by inflammatory mediators such as interleukin (IL)-1, IL-6, tumor necrosis factor (TNF)- $\alpha$, macrophage inflammatory protein 1 , and interferon (IFN) for heat production, and depends on antipyretics (IL-10, glucocorticoids, and neuropeptides) for heat dissipation [42,43]. Chaihu is prescribed as the major herbal medicine to resolve alternating chills and fever, headache, distention in the chest and flank, or loss of appetite in CM $[18,44]$. Chaihu was reported to exert its antipyretic effect through the thermoregulatory center in the hypothalamus [45]. Chaihu inhibited increases in cyclic adenosine monophosphate (c-AMP), an endopyrogen, in the hypothalamus and promoted the release of antipyretic substances [46]. Furthermore, total saikosaponins exerted potent anti-endotoxin effects with a simultaneous reduction in body temperature elevation in vivo [47]. All of these beneficial effects can be attributed to the maintenance of cellular homeostasis, a key process regulated by autophagy.

In liver ischemia-reperfusion injury, autophagy induction attenuated the organ damage, and delayed inflammatory or oxidative damage [48]. Furthermore, autophagy suppression was found to be a response to excessive alcohol intake, which might be a reason for the abnormal protein aggregation observed in liver diseases [40]. In vitro studies further showed a dysfunction of autophagy in cells with hepatitis $C$ virus infection $[48,49]$. Autophagy was also found to regulate the immunological responses to invading microorganisms [50]. Another study showed that plasmacytoid dendritic cells recognized viruses via Toll-like receptors (TLRs) with a requirement for autophagy [51]. In addition, defective autophagy was involved in inflammatory diseases such as systemic lupus erythematosis and Crohn's disease [52,53]. Emerging evidence has suggested roles for autophagy in immunological responses including antimicrobial activity, antigen presentation, cytokine production, and regulation of lymphocytes [50,54]. For example, disruption of the virulence factor from the HSV-1 virus, which inhibited the host autophagy proteins, could prevent fatal encephalitis [55]. In addition, autophagy exhibited protective functions in the spleen, bone marrow, or liver through activation of immune responses such as detoxification and degradation of toxins and inflammatory proteins [56-58].

Table 1 Comparisons of CM applications, pharmacological actions, and autophagy effects of Chaihu

\begin{tabular}{lll}
\hline CM applications & Pharmacological effects & Autophagic effects \\
\hline Improvement of alternating chills and fever & $\begin{array}{l}\text { Antipyresis Antibacteria, antivirus, and } \\
\text { anti-endotoxin Immunomodulation }\end{array}$ & $\begin{array}{l}\text { Immunomodulation Anti-pathogens Modulation } \\
\text { of cytokine secretion Removal of toxic mutant } \\
\text { proteins and aggregates }\end{array}$ \\
& &
\end{tabular}

Modulation of inflammatory symptoms and diseases

Immunomodulation Antibacteria and antivirus Modulation of cytokine secretion

Reduction of distention and pain in the chest and flank Improvement of digestive functions: loss of appetite, dyspepsia, and flatulence

Improvement of circulation or stasis of blood and body fluid, and accumulation of phlegm

Improvement of emotional instability
Hepatoprotection Anti-inflammation Anti-fibrosis Promotion of pancreatic digestive enzyme secretion

Promotion of cancer cell death Reduction in cancer cell proliferation Immunomodulation, apoptosis, and anti-angiogenesis

Reduction in plasma lipid levels Hormonal regulation Glucose metabolism
Immunomodulation by pathogen and cytokine control Removal of abnormal protein aggregates Detoxification and degradation of toxins and inflammatory proteins

Cellular catabolism for removal of waste materials Immunomodulation Anti-pathogens Removal of toxic mutant proteins and aggregates Regulation of lipid metabolism

Maintenance of genomic stability Promotion of autophagic cell death Elimination of damaged proteins and cytotoxic substances

Regulation of lipid metabolism Removal of toxic mutant proteins and aggregates 
Chaihu regulated the immune responses against invading pathogens by stimulating the secretion of glucocorticoids and inhibiting inflammation and anaphylaxis $[59,60]$, and was involved in inflammatory processes such as infiltration, capillary permeability, and release of cytokines [46]. Chaihu or its component saikosaponins eliminated exogenous pyrogens through their antibacterial properties [61], and possessed antiviral activities toward hepatitis B [62], human coronavirus 229E [9], influenza virus [11], and respiratory syncytial virus [63]. Ssd reduced the levels of cyclooxygenase and lipoxygenase in vitro, promoted IL-2 and IL-4 production, and inhibited IL-6, TNF- $\alpha$, and IFN- $\gamma$ expression in mouse T lymphocytes $[64,65]$. The prominent anti-inflammatory effects of Chaihu could be mediated through autophagy induction, a key process for pathogen elimination and immunity regulation. Our group was the first to report the autophagic activities of Chaihu and Ssd [16]. We hypothesized that Chaihu harmonizes the exterior and interior of the human body and soothes gan qi stagnation through autophagy induction.

\section{Chaihu-induced autophagy alleviates gan qi stagnation}

In CM theory, Chaihu soothes stagnation of gan $q i$ and promotes circulation of $q i$, and thus alleviates distention and pain in the chest and flank, menstrual dysregulation, impaired digestive functions such as loss of appetite, dyspepsia, flatulence, and regurgitation, and emotional instabilities such as depression, anxiety, and insomnia [18]. Chaihu is used to treat diseases related to the digestive system, e.g., hepatitis, liver cirrhosis, cholecystitis, pancreatitis, gynecological diseases, and hyperlipidemia [5].

Saikosaponins alleviated hepatocytes from oxidative and inflammatory stresses, and inhibited liver fibrosis [66]. Further studies demonstrated the protective effects of saikosaponins in reducing lipid peroxidation in hepatocytes [67], regulating intracellular calcium levels to prevent hepatocyte injury [68], suppressing activation of hepatic stellate cells as the major matrix-producing cells in liver fibrosis [69,70], and reducing collagen I deposition in the rat liver [71]. Saikosaponins exhibited regulatory effects on cytokines such as ILs, TNF, and IFN $[64,65]$, inhibitory effects on infiltration of macrophages and $\mathrm{T}$ lymphocytes [72], and bidirectional modulation of splenic $\mathrm{T}$ lymphocyte proliferation [64]. These findings suggest that the hepatoprotective effects of Chaihu and saikosaponins are related to improvement of gan qi stagnation. In addition to liver diseases, Chaihu is commonly used for chronic pancreatitis [73]. Saikosaponins exhibited potent stimulatory effects on pancreatic enzyme secretion in rats [74]. Chai-hu-shu-gan powder inhibited the expression of nuclear factor- $\mathrm{kB}$ (NF-kB) and TNF- $\alpha$ mRNA in the pancreas to achieve anti-inflammatory and antifibrotic effects [75]. Moreover, the same prescription reduced the abnormally high plasma level of cholecystokinin in chronic pancreatitis, improved the gastric movement, and avoided nausea and flatulence [76,77].

In liver ischemia-reperfusion injury, autophagy induction attenuated the ischemic and reperfusion damage to the organ, probably because a decrease in autophagy would lead to accumulation of dysfunctional mitochondria, resulting in cellular damage and failure in energy production, and eventually cell death [48]. In liver disease, suppression of autophagy caused abnormal protein aggregation [40]. In liver fibrosis, autophagy activation might be beneficial to the recovery of the liver function [78]. All of these findings indicate that Chaihu-induced autophagy might relieve liver disease-related symptoms through anti-inflammatory, organ-protective, and aggregate removal functions, which are related to alleviation of gan qi stagnation.

Chaihu-mediated autophagy intervenes in carcinogenesis In CM theory, tumor formation is the result of stasis of xue (blood), retention of jin ye (fluid), and accumulation of tan (phlegm) [79]. A recent study demonstrated the anticancer effects of Ssa and Ssd via autophagy

\begin{tabular}{|c|c|}
\hline Cancer & Chaihu-containing prescriptions \\
\hline \multirow[t]{7}{*}{ Hepatocellular cancer } & Xiao Chaihu Decoction \\
\hline & Supplemented Da Chaihu Decoction \\
\hline & Si ni Powder combined with Liu jun zi Decoction \\
\hline & Supplemented Xiao yao Powder \\
\hline & No. 1 anticancer formula \\
\hline & Chaihu zhe chong Decoction \\
\hline & Experienced prescription \\
\hline \multirow[t]{2}{*}{ Pancreatic cancer } & Xiao Chaihu Decoction \\
\hline & Experienced prescription \\
\hline Gall bladder cancer & Shu gan li dan Decoction \\
\hline \multirow[t]{4}{*}{ Breast cancer } & Yi qi shu gan Decoction \\
\hline & Xiao ru Decoction \\
\hline & $\begin{array}{l}\text { Supplemented Xiao yao powder combined } \\
\text { with Si jun zi Decoction }\end{array}$ \\
\hline & Experienced prescription \\
\hline \multirow[t]{2}{*}{ Cervical cancer } & Jia wei xiao yao Powder \\
\hline & Chaihu gui zhi Decoction \\
\hline Thyroid carcinoma & Jia xian ping Decoction \\
\hline \multirow[t]{2}{*}{ Esophageal carcinoma } & Jin fo yin \\
\hline & Er chen xuan fu Decoction \\
\hline Gastric cancer & $\begin{array}{l}\text { Chaihu shu gan Decoction combined with } \\
\text { Xi shu jian }\end{array}$ \\
\hline
\end{tabular}


induction and autophagic cell death [16]. In addition, Chaihu is a commonly prescribed herb in contemporary formulations (Table 2) with preventive or therapeutic effects on cancer [80]. Patients treated with "xiao Chaihu" decoction exhibited a significantly lower incidence of hepatocellular carcinoma [81], reductions in cancer pain and tumor size $[82,83]$, and prevention of liver cancer relapses [84]. The decoction had multiple functions in immunomodulation, apoptosis, and anti-angiogenesis [85-87].

The signaling pathway of autophagy is associated with the key regulatory proteins of carcinogenesis, such as tumor suppressor gene p53, phosphatase and tensin homolog (PTEN), death-associated protein kinase, and proto-oncoprotein B-cell CLL/lymphoma 2 (Bcl-2) $[39,88]$. Autophagy was responsible for massive cancer cell death in vitro and in vivo [89-91]. Autophagic inducers also promoted autophagic cell death in tumors or augmented the efficacy of chemotherapeutic agents when used in combination during cancer therapy $[92,93]$. By eliminating genomic mutations, damaged proteins, and cytotoxic substances, autophagy protected cells against cancers [94]. However, the roles of autophagy in cancers remain controversial, because autophagy might promote tumor growth by providing energy to poorly-vascularized tumor cells [95].

Despite its adaptive and pro-survival roles, autophagy can lead to type II programmed cell death [96]. Autophagy promoted autophagic cell death in cells [97], and killed apoptosis-resistant cancer cells under chemotherapy [98]. Moreover, autophagy was associated with massive cancer cell death in cancerous tissues derived from different organs $[99,100]$. Ssd was able to induce autophagic cell death in a panel of apoptosis-resistant cells via direct inhibition of SERCA [16]. The anticancer effects of Chaihu can be attributed to its autophagyinducing ability.

\section{Chaihu-mediated autophagy modulates stress hormone-regulated metabolism}

Chaihu could mediate its protective effects on gan $q i$ stagnation-induced emotional instability through lipid metabolism and hormonal regulation [101]. In fact, analyses of plasma metabolites in a rat model of gan $q i$ stagnation stimulated by chronic immobilization stress revealed elevated levels of lactic acid, saturated fatty acid, and blood sugar, and reduced levels of unsaturated fatty acid and high density lipoprotein [102]. Another study applied stress to a macaque model with premenstrual syndrome, and demonstrated increased plasma levels of serotonin (5-HT), noradrenalin, and prolactin [103].

As a regulator of lipid and glucose metabolism [104], loss of autophagy caused abnormal accumulation of lipids in mouse hepatocytes and a significant increase in plasma triglycerides, with reductions in fatty acid betaoxidation [105] and pancreatic $\beta$-cell mass [106]. Coincidently, saikosaponins increased hepatic uptake of cholesterol and decreased plasma levels of cholesterol and triglycerides [107]. Furthermore, a study on depressive patients revealed correlations between the plasma levels of cholesterol, triglycerides, and serum neurotransmitters, and depression [108]. As saikosaponins were able to reduce the plasma levels of cholesterol, triglycerides, and phospholipids [107], Chaihu might attenuate depressive symptoms by regulating metabolite, hormone, and neurotransmitter levels via autophagy-mediated lipid metabolism in the human body.

\section{Conclusions}

The function of Chaihu in harmonizing the exterior and interior of the body is related to its pathogen control and immunomodulation properties. Furthermore, Chaihu's function in resolving gan qi stagnation might arise through its supportive roles in protecting organs, preventing damage to cells and organs, and restoring visceral and cellular metabolic conditions. All of these protective pharmacological effects of Chaihu might be attributed to its autophagy induction.

\section{Abbreviations \\ Ssa: Saikosaponin-a; Ssc: Saikosaponin-c; Ssd: Saikosaponin-d; ER: Endoplasmic reticulum; PTEN: Phosphatase and tensin homolog; TLRs: Toll-like receptors; BCl-2: B-cell CLL/lymphoma 2; IL: Interleukin; TNF: Tumor necrosis factor; IFN: Interferon; C-AMP: Cyclic adenosine monophosphate; SERCA: Sarcoplasmic/ endoplasmic reticulum calcium ATPase pump; NF-kB: Nuclear factor-kB; \\ CM: Chinese medicine; Atg: Autophagy-related gene; mTOR: Mammalian target of rapamycin; 5-HT: 5-hydroxytryptamine.}

Competing interests

The authors declare that they have no competing interests.

\section{Authors' contributions}

VKWW conceived and planned the review. BYKL and JFO carried out the review plan and wrote the manuscript. All authors read and approved the final manuscript.

\section{Acknowledgment}

This work was supported by grants from the Science and Technology Development Fund (FDCT) of Macao (Project codes: 013/2012/A1 and 076/2011/A3)

\section{Author details}

'State Key Laboratory of Quality Research in Chinese Medicine, Macau University of Science and Technology, Macau, China. ${ }^{2}$ School of Chinese Medicine, Hong Kong Baptist University, Hong Kong, China.

Received: 4 March 2014 Accepted: 8 September 2014

Published: 11 September 2014

\section{References}

1. Huang Z: The overview of xiao yao powder in clinical practice. J Guangx Tradit Chin Med Univ 2009, 12:76-78.

2. Wei DY, Wang GY: The clinical application of da chaihu decoction. Mod J Integr Tradit Chin Wes Med 2013, 22:1476-1478.

3. Liu CL: Treated chronic cholecystitis alternating chills and fevers syndrome with xiao chai hu decoction in 59 cases. Guangming J Chin Med 2012, 27:63. 
4. Xuan X, Rong ZB, Liu C, Li YH, Duan LH, Li LJ, Wu ZZ: Effects of CHSGS on behavior and hippocampal monoamine neurotransmitter in Alzheimer's disease rats with liver-qi. Shenzhen J Integ Tradit Chin Wes Med 2013, 23:129-134.

5. Zhao ZZ, Xiao PG: Encyclopedia of Medicinal Plants. Shanghai: Shanghai World Publishing Corporation; 2009

6. Li TL, Du XW: The comparison of the pharmacological effect of nan Chaihu and bei Chaihu: the pilot study of anti-pyretic and hepatoprotective effect. Acta Chin Med Pharmacol 1992, 3:34-37.

7. Benito PB, Martinez MJA, Sen AMS, Gomez AS, Matellano LF, Contreras SS, Lanza AMD: In vivo and in vitro antiinflammatory activity of saikosaponins. Life Sci 1998, 63:1147-1156.

8. Yen MH, Lin CC, Yen CM: The immunomodulatory effect of saikosaponin derivatives and the root extract of Bupleurum kaoi in mice. Phytother Res 1995, 9:351-358

9. Cheng PW, Ng LT, Chiang LC, Lin CC: Antiviral effects of saikosaponins on human coronavirus 229E in vitro. Clin Exp Pharmacol Physiol 2006 33:612-616.

10. Usman MSI, Africa LJ, Akuodor GC, Ugwu TC, Osunkwo UA: Antinociceptive and antipyretic properties of the pharmaceutical herbal preparation, Radix bupleuri in rats. J Medic Plants Res 2010, 4:659-663.

11. Wang SC, Zhao HP: Effects of chaihu on antipyretic and antivirus. Lishizhen medicine mat Med Res 1998, 9:418-419.

12. Shimaoka A, Seo S, Minato H: Saponins isolated from Bupleurum falcatum L.; components of saikosaponin b. J Chem Soc Perkin 1 1975, 20:2043-2048.

13. Huang W, Zhao Y, Sun R: Research development on hepatoprotective effect and hepatotoxicity based on bupleurum saikosaponin components. Chin J Pharmacovigilance 2011, 8:38-40.

14. Kang SJ, Lee YJ, Kim BM, Kim YJ, Woo HD, Jeon HK, Chung HW: Effect of Bupleuri Radix extracts on the toxicity of 5-fluorouracil in HepG2 hepatoma cells and normal human lymphocytes. Basic Clin Pharmacol Toxicol 2008, 103:305-313.

15. Wang YS: Pharmacology and Applications of Chinese Materia Medica. Beijing: People's Health Publisher; 1983.

16. Wong VK, Li T, Law BY, Ma ED, Yip NC, Michelangeli F, Law CK, Zhang MM, Lam KY, Chan PL, Liu L: Saikosaponin-d, a novel SERCA inhibitor, induces autophagic cell death in apoptosis-defective cells. Cell Death Dis 2013, 4:e720.

17. Zhang HW, Zhou ZM: The clinical application and modern research progress of CHSGS. Lishizhen medicine and materia medica Res 2007, 18:1234-1236.

18. Liu ZW, Liu L: Essentials of Chinese Medicine. London: Foundations of Chinses Medicine. Springer; 2009

19. Wang YL, He SX, Luo JY: Progress in research on antitumor activity of saikosaponin and its mechanism. Zhong Xi Yi Jie He Xue Bao 2006, 4:98-100.

20. Yang YY, Tang YZ, Fan CL, Luo HT, Guo PR, Chen JX: Identification and determination of the saikosaponins in Radix bupleuri by accelerated solvent extraction combined with rapid-resolution LC-MS. J Sep Sci 2010 33:1933-1945

21. Zhu SH, Shimokawa S, Tanaka H, Shoyama Y: Development of an assay system for saikosaponin a using anti-saikosaponin a monoclonal antibodies. Biol Pharm Bull 2004, 27:66-71.

22. Chen JC, Chang NW, Chung JG, Chen KC: Saikosaponin-a induces apoptotic mechanism in human breast MDA-MB-231 and MCF-7 cancer cells. Am J Chin Med 2003, 31:363-377.

23. Kim BM, Hong SH: Sequential caspase-2 and caspase- 8 activation is essential for saikosaponin a-induced apoptosis of human colon carcinoma cell lines. Apoptosis 2011, 16:184-197.

24. Sun Y, Cai TT, Zhou XB, Xu Q: Saikosaponin a inhibits the proliferation and activation of $T$ cells through cell cycle arrest and induction of apoptosis. Int Immunopharmacol 2009, 9:978-983.

25. Wu WS, Hsu HY: Involvement of p-15(INK4b) and p-16(INK4a) gene expression in saikosaponin a and TPA-induced growth inhibition of HepG2 cells. Biochem Biophys Res Commun 2001, 285:183-187.

26. Wu SJ, Lin YH, Chu CC, Tsai YH, Chao JC: Curcumin or saikosaponin a improves hepatic antioxidant capacity and protects against CCl4induced liver injury in rats. J Med Food 2008, 11:224-229.

27. Shyu KG, Tsai SC, Wang BW, Liu YC, Lee CC: Saikosaponin C induces endothelial cells growth, migration and capillary tube formation. Life Sci 2004, 76:813-826.
28. Chiang LC, Ng LT, Liu LT, Shieh DE, Lin CC: Cytotoxicity and anti-hepatitis $B$ virus activities of saikosaponins from Bupleurum species. Planta Med 2003, 69:705-709.

29. Wong VK, Zhang MM, Zhou H, Lam KY, Chan PL, Law CK, Yue PY, Liu L: Saikosaponin-d enhances the anticancer potency of TNF-alpha via overcoming its undesirable response of activating NF-Kappa B signalling in cancer cells. Evid Based Complement Alternat Med 2013, 2013:745295

30. Abe H, Orita M, Konishi H, Arichi S, Odashima S: Effects of saikosaponin-d on enhanced CCl4-hepatotoxicity by phenobarbitone. J Pharm Pharmacol 1985, 37:555-559.

31. Hsu YL, Kuo PL, Lin CC: The proliferative inhibition and apoptotic mechanism of saikosaponin $d$ in human non-small cell lung cancer A549 cells. Life Sci 2004, 75:1231-1242.

32. Hsu YL, Kuo PL, Chiang LC, Lin CC: Involvement of p53, nuclear factor kappaB and Fas/Fas ligand in induction of apoptosis and cell cycle arrest by saikosaponin d in human hepatoma cell lines. Cancer Lett 2004, 213:213-221.

33. Mizushima N: Autophagy: process and function. Genes Dev 2007 $21: 2861-2873$

34. Kang C, You YJ, Avery L: Dual roles of autophagy in the survival of caenorhabditis elegans during starvation. Genes Dev 2007, 21:2161-2171.

35. Sadasivan S, Waghray A, Larner SF, Dunn WA Jr, Hayes RL, Wang KK: Amino acid starvation induced autophagic cell death in PC-12 cells: evidence for activation of caspase-3 but not calpain-1. Apoptosis 2006, 11:1573-1582.

36. Lum JJ, Bauer DE, Kong M, Harris MH, Li C, Lindsten T, Thompson CB: Growth factor regulation of autophagy and cell survival in the absence of apoptosis. Cell 2005, 120:237-248.

37. Mizushima N, Klionsky DJ: Protein turnover via autophagy: implications for metabolism. Annu Rev Nutr 2007, 27:19-40.

38. Kuma A, Hatano M, Matsui M, Yamamoto A, Nakaya H, Yoshimori T, Ohsumi $Y$, Tokuhisa T, Mizushima N: The role of autophagy during the early neonatal starvation period. Nature 2004, 432:1032-1036.

39. Levine B, Kroemer G: Autophagy in the pathogenesis of disease. Cell 2008, 132:27-42.

40. Komatsu M, Waguri S, Ueno T, Iwata J, Murata S, Tanida I, Ezaki J, Mizushima N, Ohsumi Y, Uchiyama Y, Kominami E, Tanaka K, Chiba T: Impairment of starvation-induced and constitutive autophagy in Atg7-deficient mice. J Cell Biol 2005, 169:425-434.

41. Mathew R, Kongara S, Beaudoin B, Karp CM, Bray K, Degenhardt K, Chen G, Jin S, White E: Autophagy suppresses tumor progression by limiting chromosomal instability. Genes Dev 2007, 21:1367-1381.

42. Dalal S, Zhukovsky DS: Pathophysiology and management of fever. J Support Oncol 2006, 4:9-16.

43. Kleef R, Hager ED: Fever, Pyrogens and Cancer. In Hyperthermia in Cancer Treatment: A Primer. Volume 3. Edited by Baronzio GF, Hager ED. London: Springer; 2006:276-337.

44. Han DW, Ma XH, Zhou LM, Zhao YC: The therapeutic effect of experimental liver injury by xiao yao san. Shan Xi Yi Yao Za Zhi 1976, 2:71-75.

45. Jin GT, Li B, Wang SR: Experimental study on material basis, efficacy and mechanism of antipyretic effect of Bupleuri Radix. J Chengdu Univ TCM 2013, 36:28-30.

46. Zhang YB, Liang Y, Xia AJ: The progress of pharmacological study on the anti-pyretic effect of Chaihu. China Pharmaceuticals 2011, 20:79-80.

47. Liu YH, Chen YS, Xi W, Bai J: Studies on antiendotoxin action of total saponins from radix Bupleuri. Zhong Yao Cai 2003, 26:423-425.

48. Rautou PE, Mansouri A, Lebrec D, Durand F, Valla D, Moreau R: Autophagy in liver diseases. J Hepatol 2010, 53:1123-1134.

49. Sir D, Chen WL, Choi J, Wakita T, Yen TS, Ou JH: Induction of incomplete autophagic response by hepatitis $C$ virus via the unfolded protein response. Hepatology 2008, 48:1054-1061.

50. Virgin HW, Levine B: Autophagy genes in immunity. Nat Immunol 2009 10:461-470.

51. Lee HK, Lund JM, Ramanathan B, Mizushima N, Iwasaki A: Autophagydependent viral recognition by plasmacytoid dendritic cells. Science 2007, 315:1398-1401.

52. Grossmayer GE, Munoz LE, Gaipl US, Franz S, Sheriff A, Voll RE, Kalden JR, Herrmann M: Removal of dying cells and systemic lupus erythematosus. Mod Rheumatol 2005, 15:383-390. 
53. Massey DC, Parkes M: Genome-wide association scanning highlights two autophagy genes, ATG16L1 and IRGM, as being significantly associated with Crohn's disease. Autophagy 2007, 3:649-651.

54. Ding Z, Liu S, Wang X, Khaidakov M, Dai Y, Mehta JL: Oxidant stress in mitochondrial DNA damage, autophagy and inflammation in atherosclerosis. Sci Rep 2013, 3:1077.

55. Orvedahl A, Alexander D, Talloczy Z, Sun Q, Wei Y, Zhang W, Burns D, Leib DA, Levine B: HSV-1 ICP34.5 confers neurovirulence by targeting the Beclin 1 autophagy protein. Cell Host Microbe 2007, 1:23-35.

56. Miller BC, Zhao Z, Stephenson LM, Cadwell K, Pua HH, Lee HK, Mizushima NN, Iwasaki A, He YW, Swat W, Virgin HWT: The autophagy gene ATG5 plays an essential role in B lymphocyte development. Autophagy 2008, 4:309-314.

57. Mitroulis I, Kourtzelis I, Papadopoulos VP, Mimidis K, Speletas M, Ritis K: In vivo induction of the autophagic machinery in human bone marrow cells during Leishmania donovani complex infection. Parasitol Int 2009, 58:475-477.

58. Levine $B$, Deretic $V$ : Unveiling the roles of autophagy in innate and adaptive immunity. Nat Rev Immuno/ 2007, 7:767-777.

59. Zhou QL, Zhang ZQ, Nagasawa T, Hiai S: The structure activity relationship of saikosaponins and glycyrrhizin derivatives for $\mathrm{Na}+, \mathrm{K}(+)$-ATPase inhibiting action. Yao Xue Xue Bao 1996, 31:496-501.

60. Chen RJ, Chung TY, Li FY, Yang WH, Jinn TR, Tzen JT: Steroid-like compounds in Chinese medicines promote blood circulation via inhibition of Na+/K+ -ATPase. Acta Pharmacol Sin 2010, 31:696-702.

61. Shen LL, Ye YK, Pan SL, Wu JM: Activity of monomers of pentaeyclic triterpennoids of saikosaponines against methicillin-resistant staphylococcus aureus. J Tongji UnivMed Sci 2008, 29:15-46.

62. Chang JS, Wang KC, Liu HW, Chen MC, Chiang LC, Lin CC: Sho-saiko-to (xiao-chai-hu-tang) and crude saikosaponins inhibit hepatitis $B$ virus in a stable HBV-producing cell line. Am J Chin Med 2007, 35:341-351.

63. Liao DS, Yu DW: Suppresive effect on respiratory syncytial virus through combination of Ribavirin and Chaihu injection. Chin $J$ of mis diagnostics 2003, 3:230-231

64. Kato M, Pu MY, Isobe K, Iwamoto T, Nagase F, Lwin T, Zhang YH, Hattori T, Yanagita N, Nakashima I: Characterization of the immunoregulatory action of saikosaponin-d. Cell Immunol 1994, 159:15-25.

65. Wong VK, Zhou H, Cheung SS, Li T, Liu L: Mechanistic study of saikosaponin-d (Ssd) on suppression of murine T lymphocyte activation. J Cell Biochem 2009, 107:303-315.

66. Liao $\mathrm{B}, \mathrm{Chen} \mathrm{N}$ : The study of the protective mechanism of hepatocyte in obstructive jaundice by saikosaponin. Guide of China Med 2011, 9:52-53.

67. He Y, Hu ZF, Li P, Xiao C, Chen YW, Li KM, Guo JZ, Pan L, Xiong JP: Experimental study of saikosaponin-d (SSd) on lipid peroxidation of hepatic fibrosis on rat. Zhongguo Zhong Yao Za Zhi 2008, 33:915-919.

68. Han XH, Gai XD, Xue YJ, Chen M: Effects of the extracts from Bupleurum Chinese $D C$ on intracelluar free calcium concentration and vincristine accumulation in human hepatoma BEL-7402 cells. Tumor 2006, 26:314-317.

69. Chen SA, Ben CG, Yang MJ: A clinical study on the saikosaponin on FSC activation and extracellular matrix synthesis. J Beijing University of TCM 1999, 22:31-34.

70. Moreira RK: Hepatic stellate cells and liver fibrosis. Arch Pathol Lab Med 2007, 131:1728-1734.

71. Fan J, Li X, Li P, Li N, Wang T, Shen H, Siow Y, Choy P, Gong Y: Saikosaponin-d attenuates the development of liver fibrosis by preventing hepatocyte injury. Biochem Cell Biol 2007, 85:189-195.

72. Li P, Gong YW, Zhao SP, Ming LK, Chen YW, Fu GX, Zhen GJ, Li X, Zhang $Y$ : Experimental investigation of suppressive effect of saikosaponin-d on the progression of glomerulosclerosis. Sci Technol Rev 2006, 24:37-41

73. Huang $H Q$, Feng LY: Cognition of traditional Chinese medicine about chronic pancreatitis and its treating progression. Mod J Integrated Traditional Chin West Med 2007, 16:3762-3763.

74. Yang $W X, Y u Y$, Wang $H$, Zhao YY, Liang $H, W u X Z$ : Kinetics of enzymes secretion and mechanism stimulated by effective component of bupleurum in rat pancreatic acini. Modernization of Traditional Chinese Medicine and Materia Medica-World. Sci Technolx 2001, 3:21-24.

75. Chen Y, Zhou XL, Xue CR: Therapeutic effects and mechanisms of chaihushugan decoction in experimental chronic pancreatitis rats. Chi J Sur Integrated Traditional Wes Med 2010, 16:330-333.
76. Liu J, Zhao Z, Xue CR: Effect of chaihu shugan pulvis on dysfunction of pancreatic exocrine secretion in patients with chronic pancreatitis. Chinese J Sur Integrated Traditional and We Med 2010, 16:275-277.

77. Miyasaka K, Ohta M, Kanai S, Yoshida Y, Sato N, Nagata A, Matsui T, Noda T, Jimi A, Takiguchi S, Takata Y, Kawanami T, Funakoshi A: Enhanced gastric emptying of a liquid gastric load in mice lacking cholecystokinin- $B$ receptor: a study of CCK-A, $B$, and $A B$ receptor gene knockout mice. J Gastroenterol 2004, 39:319-323.

78. Mao YL, Chen RR, Yang HY, Zhang JC, Zhang YD, Ma JH, Sang XT, Lu X, Zhong SX, Huang JF: Autophagy in fibrotic and postoperative remnant liver in rat. Zhongguo Yi Xue Ke Xue Yuan Xue Bao 2008, 30:421-425.

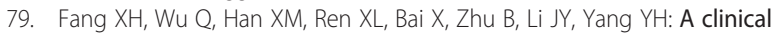
study of chaihu shugan powder in the treatment of malignant tumor patients with depression. J Chin Oncol 2013, 19:726-729.

80. Yang JK: Xian Dai Zhong Yi Zhong Liu Xue (Modern oncology study-Chinese medicine). Shanghai: Shanghai University of Traditional Chinese Medicine Press; 2004.

81. Oka H, Yamamoto S, Kuroki T, Harihara S, Marumo T, Kim SR, Monna T, Kobayashi K, Tango T: Prospective study of chemoprevention of hepatocellular carcinoma with Sho-saiko-to (TJ-9). Cancer Lett 1995, 76:743-749.

82. Chang MY: Treatment of 15 cases of primary liver cancer by using supplemented xiao-chai-hu decoction. J Practical Trad Chin Med 1995, $1: 14$.

83. Zhao HY: Clinical observation of the treatment of primary liver cancer by using xiao-chai-hu decoction. J Tradit Chin Med 1995, 18:32.

84. Li SJ, Li L, Yi C: Clinical observation of the preventive effect of xiao-chaihu-pian after surgery of liver cancer, attached with 40 case reports. J Chengdu Unv Tarditional Chin Med 2001, 25:16-18.

85. Inada Y, Watanabe K, Kamiyama M, Kanemitsu T, Clark WS, Lange M: In vitro immunomodulatory effects of traditional Kampo medicine (sho-saiko-to: SST) on peripheral mononuclear cells in patients with AIDS. Biomed Pharmacotherapy 1990, 44:17-19.

86. Motoo Y, Sawabu N: Antitumor effects of saikosaponins, baicalin and baicalein on human hepatoma cell lines. Cancer Lett 1994, 86:91-95.

87. Liang JJ, Yin DF, Zhou LJ: Experimental study on the expression of VEGF of the minor Bupleuri Decoction in mice with Lewis lung cancer cells. Acta Chin Med Pharmacol 2008, 36:15-17.

88. Pattingre $\mathrm{S}$, Levine $\mathrm{B}$ : $\mathrm{Bcl}-2$ inhibition of autophagy: a new route to cancer? Cancer Res 2006, 66:2885-2888.

89. Bursch W, Ellinger A, Kienzl H, Torok L, Pandey S, Sikorska M, Walker R, Hermann RS: Active cell death induced by the anti-estrogens tamoxifen and ICI 164384 in human mammary carcinoma cells (MCF-7) in culture: the role of autophagy. Carcinogenesis 1996, 17:1595-1607.

90. Onodera R, Motoyama K, Tanaka N, Ohyama A, Okamatsu A, Higashi T, Kariya R, Okada S, Arima H: Involvement of autophagy in antitumor activity of folate-appended methyl-beta-cyclodextrin. Sci Rep 2014, 4:4417.

91. Chen Y, Liersch R, Detmar M: The miR-290-295 cluster suppresses autophagic cell death of melanoma cells. Sci Rep 2012, 2:808.

92. Law BY, Wang M, Ma DL, Al-Mousa F, Michelangeli F, Cheng SH, Ng MH, To KF, Mok AY, Ko RY, Lam SK, Chen F, Che CM, Chiu P, Ko BC: Alisol B, a novel inhibitor of the sarcoplasmic/endoplasmic reticulum $\mathrm{Ca}(2+)$ ATPase pump, induces autophagy, endoplasmic reticulum stress, and apoptosis. Mol Cancer Ther 2010, 9:718-730.

93. Kondo $Y$, Kanzawa $T$, Sawaya $R$, Kondo $S$ : The role of autophagy in cancer development and response to therapy. Nat Rev Cancer 2005 5:726-734.

94. DiPaola RS, Dvorzhinski D, Thalasila A, Garikapaty V, Doram D, May M, Bray K, Mathew R, Beaudoin B, Karp C, Stein M, Foran DJ, White E: Therapeutic starvation and autophagy in prostate cancer: a new paradigm for targeting metabolism in cancer therapy. Prostate 2008, 68:1743-1752.

95. Hippert MM, O'Toole PS, Thorburn A: Autophagy in cancer: good, bad, or both? Cancer Res 2006, 66:9349-9351.

96. Shimizu S, Yoshida T, Tsujioka M, Arakawa S: Autophagic cell death and cancer. Int J Mol Sci 2014, 15:3145-3153.

97. Yu L, Alva A, Su H, Dutt P, Freundt E, Welsh S, Baehrecke EH, Lenardo MJ: Regulation of an ATG7-beclin 1 program of autophagic cell death by caspase-8. Science 2004, 304:1500-1502.

98. Debnath J, Baehrecke EH, Kroemer G: Does autophagy contribute to cell death? Autophagy 2005, 1:66-74. 
99. Mujumdar N, Saluja AK: Autophagy in pancreatic cancer: an emerging mechanism of cell death. Autophagy 2010, 6:997-998.

100. Opipari AW Jr, Tan L, Boitano AE, Sorenson DR, Aurora A, Liu JR: Resveratrol-induced autophagocytosis in ovarian cancer cells. Cancer Res 2004, 64:696-703.

101. Li D, Jiang T, Fan HQ, Liang WN, Xiong KC, Tang CP: Influence of chaihushugan powder on lipid metabolism and liver function in nonalcoholic fatty liver rats. Zhong Yao Yao Li Yu Lin Chuang 2013, 29:8-12.

102. Luo HG: Studies of prescriptions corresponding to syndromes of xiaoyaosan decoction based on metabonomics. In PhD thesis. Beijing: Beijing University of Traditional Chinese Medicine, Chinese Medicine Department; 2007.

103. Shi ZF: The new evidence of the hypothesis of liver governs normal flow of qi relates to monoamine neurotransmitter and sex hormone and their regulative hormone. In Master thesis. Shan Dong: Shan Dong University of Traditional Chinese Medicine, Traditional Chinese Medicine Department; 2002.

104. Kotoulas OB, Kalamidas SA, Kondomerkos DJ: Glycogen autophagy in glucose homeostasis. Pathol Res Pract 2006, 202:631-638.

105. Singh R, Kaushik S, Wang Y, Xiang Y, Novak I, Komatsu M, Tanaka K, Cuervo AM, Czaja MJ: Autophagy regulates lipid metabolism. Nature 2009, 458:1131-1135.

106. Jung HS, Chung KW, Won Kim J, Kim J, Komatsu M, Tanaka K, Nguyen YH, Kang TM, Yoon KH, Kim JW, Jeong YT, Han MS, Lee MK, Kim KW, Shin J, Lee MS: Loss of autophagy diminishes pancreatic beta cell mass and function with resultant hyperglycemia. Cell Metab 2008, 8:318-324.

107. Yamamoto M, Kumagai A, Yamamura Y: Structure and action of saikosaponins isolated from Bupleurum falcatum L. II. Metabolic actions of saikosaponins, especially a plasma cholesterol-lowering action. Arzneimittelforschung 1975, 25:1240-1243.

108. Yuan YG, Zhang XB, Wu AQ, Zhang SN, Chen YQ: The relationship between plasma monoamine neurotransmitters and serum lipid concentrations in depressive patients. J Clin Psychological Med 2003, 13:67-68.

doi:10.1186/1749-8546-9-21

Cite this article as: Law et al:: Autophagic effects of Chaihu (dried roots of Bupleurum Chinense DC or Bupleurum scorzoneraefolium WILD).

Chinese Medicine 2014 9:21.

\section{Submit your next manuscript to BioMed Central and take full advantage of:}

- Convenient online submission

- Thorough peer review

- No space constraints or color figure charges

- Immediate publication on acceptance

- Inclusion in PubMed, CAS, Scopus and Google Scholar

- Research which is freely available for redistribution 